\title{
Benefits of Climate-Change Mitigation for Reducing the Impacts of Sea-Level Rise in G-20 Countries
}

\author{
Sally Brown $^{\dagger *}$, Robert J. Nicholls ${ }^{\dagger}$, Anne K. Pardaens ${ }^{\ddagger}$, Jason A. Lowe ${ }^{\ddagger \S}$,

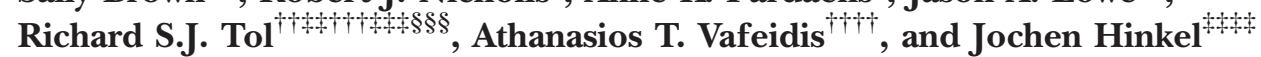 \\ ${ }^{\dagger}$ Faculty of Physical Sciences and Engineering \\ University of Southampton \\ ${ }^{*}$ Met Office Hadley Centre \\ Exeter EX1 3PB, England, U.K.
} Southampton SO17 1BJ, England, U.K

${ }^{\S}$ Priestley International Centre for Climate University of Leeds

Leeds LS2 9JT, England, U.K.

${ }^{\S}$ Department of Spatial Economics

Vrije Universiteit

Amsterdam, The Netherlands

${ }^{\$ \S \S}$ Payne Institute of Earth Resources

Colorado School of Mines

Golden, CO 80401, U.S.A.
"Department of Economics

University of Sussex

Falmer, Brighton BN1 9RH, England, U.K.

†T Tinbergen Institute

Amsterdam, The Netherlands

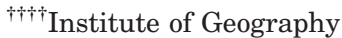

Christian-Albrechts University

Kiel, Germany

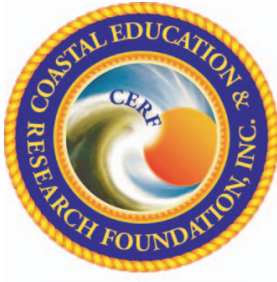

www.cerf-jcr.org

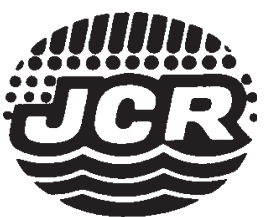

www.JCRonline.org

\begin{abstract}
Brown, S.; Nicholls, R.J.; Pardaens, A.K.; Lowe, J.A.; Tol, R.S.J.; Vafeidis, A.T., and Hinkel, J., 2019. Benefits of climatechange mitigation for reducing the impacts of sea-level rise in G-20 countries. Journal of Coastal Research, 35(4), 884895. Coconut Creek (Florida), ISSN 0749-0208.

This paper assesses the potential benefits of climate-change mitigation in reducing the impacts of sea-level rise over the 21st century in G-20 countries (excluding the European Union as a whole), using the Dynamic Interactive Vulnerability Assessment model. Impacts of the expected number of people flooded annually and wetland losses were assessed. To assess the benefits of mitigation, it was assumed that defences were not upgraded during the study. Globally, with a sealevel rise of $0.68 \mathrm{~m}$ by the $2080 \mathrm{~s}$ (with respect to $1980-99$ ), representing a potential future with limited climate-change mitigation, and with the Special Report on Emissions Scenarios A1 socio-economic scenario, 123 million additional people could be flooded annually and 39\% of present global wetland stock could be lost. For a $0.19-\mathrm{m}$ rise in sea level, associated with a substantial reduction in emissions, the number of people flooded could be reduced to $13 \mathrm{million} / \mathrm{y}$, with $21 \%$ of global wetland stock loss, unless new wetlands emerge. Collectively, non-Annex 1 G-20 countries experience a disproportionately higher number of people flooded in their nations compared with the proportion of population flooded globally. The greatest wetland losses for G-20 countries are projected for Australia, Indonesia, and the United States. Thus, G-20 nations with the highest emissions or gross domestic product frequently do not experience the greatest impacts, despite some of these nations being potentially more able to pay for adaptation.
\end{abstract}

ADDITIONAL INDEX WORDS: Adaptation, wetland loss, expected number of people at risk from flooding, equity.

\section{INTRODUCTION}

Coastal zones contain large populations and valuable ecosystems that are threatened by sea-level rise (SLR) (McGranahan, Balk, and Anderson, 2007; Small and Nicholls, 2003). Rising sea levels could lead to increased flooding, saltwater intrusion, increased shoreline erosion, and wetland loss (Nicholls, Woodroffe, and Burkett, 2009; Wong et al., 2014). Human-induced pressures, for example groundwater extraction, can locally exacerbate these effects (Wong et al., 2014). It is therefore important to understand rates of potential SLR, who and what may be affected, and the potential benefits of climate-change mitigation for coastal zones around the world.

Numerous studies have analysed potential exposure, risks, or losses due to future SLR at local, regional, or global levels,

DOI: 10.2112 /JCOASTRES-D-16-00185.1 received 6 October 2016; accepted in revision 12 September 2018; corrected proofs received 3 December 2018.

*Corresponding author: sb20@soton.ac.uk

${ }^{\circ}$ Coastal Education and Research Foundation, Inc. 2019 with a range of input conditions and uncertainties. Historical and recent SLR and coastal change have been recorded (e.g., by tide gauges) and mapped (e.g., via remote sensing; Gutierres et al., 2016). Future impacts of projected SLR have also been modelled numerically. For instance, Hinkel et al. (2014) projected that without adaptation, $0.2-4.6 \%$ of the global population could be expected to be flooded annually, with a SLR of between 0.25 and $1.23 \mathrm{~m}$ by 2100 (relative to 1980-99). This number could be considerably reduced with adaptation. In the United States alone, a SLR of $0.9 \mathrm{~m}$ by 2100 could result in an area of land flooded that contains 4.2 million people unless preventative measures are undertaken (Hauer, Evans, and Mishra, 2016). In China, $70 \%$ of cities are in coastal areas, many of which have rapid population growth. Many of these cities are in low-lying areas and are at risk from future flooding, erosion, and land subsidence (Chen, 1997), particularly where there is insufficient protection or regulation to reduce risk. Hardy and Nuse (2016) found that the countries with the highest emissions are the most exposed to SLR in terms of land 
loss over multimillenia (in absolute numbers, mainly due to their size). Additionally, by studying 84 developing countries, Dasgupta et al. (2009) found that tens of millions of people are likely to be displaced by SLR during this century, with $1.28 \%$ of the global population from these countries alone affected with 1 $\mathrm{m}$ of SLR without shoreline protection. The greatest projected wetland losses (as a percentage) were reported for the Middle East, North America, East Asia, and the Pacific region. At country level, the highest proportional losses were projected for Vietnam, Jamaica, and Belize. Kirwan and Megonigal (2013) analysed feedback in wetland systems under SLR. They found that human interaction and socioeconomic conditions affect wetland transgression from lowland to adjacent uplands under SLR. Many other studies have also found that for both population and ecosystems, human intervention or adaptation to reduce risk can greatly influence impacts.

Only a few studies have focused on assessing the relationship between the proportion of global impacts projected for a nation and its contribution to global emissions or a nation's ability to adapt (here it is assumed that the ability to adapt is related to a nation's gross domestic product [GDP] per capita; that is, a greater GDP per capita means that a nation is more able to adapt to the effects of SLR. However, it is acknowledged that this is a simple measure and that some nations may have other pressing issues that require investment. Furthermore, some nations may be exposed to multiple climate threats and choose to prioritise other noncoastal adaptation, such as improved resilience to pluvial and fluvial flooding).

For the period 1900 to 2010, the long-term trend in global mean SLR has been estimated to be $1.7 \pm 0.2 \mathrm{~mm} / \mathrm{y}$ (Church et al., 2013). Part of this rise was due to natural changes, but a proportion was attributable to human-induced climate change (Church and White, 2011; Jevrejeva, Grinsted, and Moore, 2009). The rate of future SLR is uncertain, with the Intergovernmental Panel on Climate Change's Fifth Assessment Report (IPCC AR5) projecting a rise of between $0.28 \mathrm{~m}$ and $0.98 \mathrm{~m}$ by 2100 relative to $1986-2005$, depending on emissions scenario and other uncertainties (Church et al., 2013). Although the benefits of coastal adaptation (i.e. the process of adjusting to actual or expected climate and its effects, such as through building sea walls or raising infrastructure) have been well documented (e.g., Wong et al., 2013), research into the benefits of climate-change mitigation (i.e. a reduction in the source of greenhouse gas emissions) in coastal zones is more limited. However, the benefits of climate-change mitigation for reducing the rate of SLR are known to become more apparent as time progresses (e.g., Nicholls and Lowe, 2004; Nicholls et al., 2018). The role of mitigation for coastal impacts is particularly important, given the Paris Agreement (United Nations, 2015) aims to hold "the increase in the global average temperature to well below $2^{\circ} \mathrm{C}$ above preindustrial levels and pursuing efforts to limit the temperature increase to $1.5^{\circ} \mathrm{C}$ above pre-industrial levels." Sea levels, however, will continue to rise under a future of climate-change mitigation even once global surface temperatures are stabilised (known as the commitment to SLR). This is due to the thermal inertia of the oceans and the time for land-based ice masses to reach new equilibrium states (e.g., Nicholls and Lowe, 2004). Therefore, adaptation remains essential. As the benefits of adaptation or climate-change mitigation operate over different timescales (Berry et al. 2015; Swart and Raes, 2007), it is more difficult to assess the benefits of mitigation in coastal settings.

Various commentators (e.g., Den Elzen, Hof, and Roelfsema, 2013; United Nations, 2011) have suggested that developed countries, including G-20 nations, have an important role in climate-change mitigation and policy. This is because the G-20 countries are responsible for approximately three quarters of the world's carbon dioxide emissions ( $c f$. UNFCCC, 2013; World Bank, 2016a). Hence the aim of this paper is to investigate the potential impacts of SLR under future emissions scenarios that represent different degrees of climate-change mitigation at global, G-20, and national levels. This will be achieved by analysing (1) the expected number of people flooded per year (ENPF/y) and wetland losses without additional adaptation; (2) the relationship of these impacts in G-20 nations to national contributions of global carbon dioxide emissions and GDP; (3) the benefits of climate-change mitigation in synergy with adaptation. These investigations will help assess who or what is at risk in the world's major economies, and how they may benefit through climate-change mitigation.

This paper is structured as follows. First, the scenarios of SLR are described. A complementary socioeconomic scenario is also presented. Second, the impacts modelling approach is discussed. Third, the impacts of SLR and socioeconomic change are analysed. Fourth, the discussion analyses the results in the context of emissions and GDP, and also climate-change mitigation in synergy with adaptation. Other implications are then considered.

\section{METHODS}

Impacts were assessed using sea-level and socioeconomic scenarios in a coastal impacts model.

\section{Geographic Scale Evaluated}

Impacts were analysed globally and for G-20 nations. Nineteen of the G-20 nations were considered: Argentina, Australia, Brazil, Canada, China, France, Germany, India, Indonesia, Italy, Japan, Korea, Mexico, Russia, Saudi Arabia, South Africa, Turkey, the United Kingdom, and the United States (Figure 1). The 20th member (the European Union as a whole) was not analysed to avoid double counting. These 19 countries account for $61 \%$ of the world's coastlines and $65 \%$ of today's global population (extracted from the Dynamic Interactive Vulnerability Assessment model [DIVA] [Vafeidis et al., 2008]—see "Impacts Model" section below). G-20 countries are divided into Annex 1 (industrialised economies and those who were members of the Organisation for Economic Co-operation and Development in 1992, plus some countries with economies in transition [UNFCCC, 2013]) and non-Annex 1 countries (mostly developing nations, some seen to be particularly vulnerable to climate change or are economically vulnerable as they rely heavily on fossil fuels [UNFCCC, 2013]). The latter group includes Argentina, Brazil, China, India, Indonesia, Korea, Mexico, Saudi Arabia, and South Africa.

\section{Scenarios}

The SLR and socioeconomic scenarios used in this modelling study are described in this section. The magnitude and range of SLR is the source of uncertainty assessed in this analysis (other 


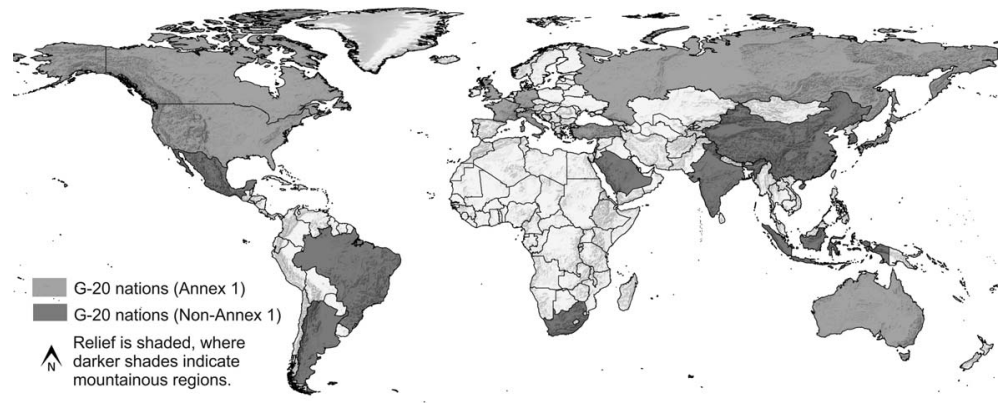

Figure 1. The 19 G-20 nations analysed (the European Union is excluded to avoid double counting), divided into Annex 1 and non-Annex 1 countries. Maps extracted from Vafeidis et al. (2008) and Natural Earth (2017).

aspects of uncertainty are noted under "Further Considerations").

\section{Sea-Level Rise}

The research presented in this paper uses two scenarios of SLR, a "high" and a "low" scenario (with uncertainty ranges), representing scenarios of different degrees of climate-change mitigation. These scenarios were generated especially for this study. The associated climate projections were from an earth system ensemble (ESE), which was an ensemble of opportunity that was created from previous studies. The model ensemble consists of 57 variants of the HadCM3C coupled climate model (Booth et al., 2012, 2013), which is based on the HadCM3 model (Gordon et al., 2000) (where the ocean has a $1.25^{\circ} \times 1.25^{\circ}$ horizontal resolution) with modifications, including an interactive carbon cycle, the indirect effects of aerosols, and flux adjustment (Booth et al., 2012). These ensembles are designed to explore climate uncertainty through perturbing parameters in the model subgrid-scale representations of physical processes.

For IPCC AR5, Church et al. (2013) gives ranges of projected SLR derived from an ensemble of different climate models (a multimodel ensemble) together with results from processbased models of land-based ice changes. They also include terms (taken from the literature) for ice-sheet rapid dynamic change (i.e. change in flow speed and discharge of the ice sheets) and land water storage. Their projections span several emissions scenarios and they give the 5 th to 95 th percentiles of model results for each emissions scenario. This is known as the "likely range" (Church et al., 2013) and indicates the assessed likelihood as being 66-100\% probability of the event occurring.

The high- and low-SLR scenarios were obtained from the ESE climate ensembles, which have median temperature increases of $3.7^{\circ} \mathrm{C}$ and $2.0^{\circ} \mathrm{C}$ respectively, relative to preindustrial times. These global mean SLR projections combine thermal expansion and land-based ice melt, the latter following Meehl et al. (2007), as this was the most appropriate methodology available at the time of study. In comparison with the most recent IPCC report (Church et al., 2013), this provides a relatively low contribution from land ice melt, with no component from ice-sheet rapid dynamic change.

The low-SLR scenario spans a range of $0.21 \mathrm{~m}$ to $0.44 \mathrm{~m}$ in 2100 relative to $1980-99$ (for the 10 th to 90 th percentile model range), with a central value of $0.31 \mathrm{~m}$. This scenario is broadly representative of one with strong climate-change mitigation and thus a large reduction in emissions. In Church et al. (2013), the most stringent climate-change mitigation scenario is representative concentration pathway (RCP) 2.6. This spans $0.28 \mathrm{~m}$ to $0.61 \mathrm{~m}$ in 2100 relative to $1986-2005$ (for the 5 th to 95th percentile model range), with a central value of $0.44 \mathrm{~m}$.

The high-SLR scenario has an associated median temperature rise of $3.7^{\circ} \mathrm{C}$, and is broadly typical of a climate scenario with limited climate-change mitigation. An additional component was included in this SLR scenario to span higher rises, which account for potential ice-sheet rapid dynamic change contributions, on the basis of Church et al. (2013). By 2100 , $0.03,0.10$, and $0.19 \mathrm{~m}$ of SLR were added for the 10th, $50 \mathrm{th}$, and 90th percentiles respectively. This gives the total projection of SLR by 2100 for the high scenario as being between $0.31 \mathrm{~m}$ and $0.79 \mathrm{~m}$ (for the 10th to 90th percentile model range), with a central value of $0.51 \mathrm{~m}$. This spans the range given in Church et al. (2013) for the RCP4.5 and RCP6.0 scenarios. The central SLR value for the high SLR scenario is closer to that for RCP4.5, but the 90th percentile value is greater than the upper RCP6.0 value.

Impact projections were made using the resulting 10 th, 50 th, and 90th percentiles of the low- and high-SLR projections (Figure 2). A "no global SLR" scenario was also included for comparison purposes, so that the effect of land-level change could be analysed.

\section{Socioeconomic Change}

In the coastal impacts model, population density and GDP per capita were distributed to each segment of coast (Vafeidis et al., 2008; see "Impacts Model") on the basis of conditions in the base year (1995) (CIESIN et al., 2000). This reflects internal variations within a country. For instance, coastal zones tend to be more densely populated than areas farther inland (Small and Nicholls, 2003). GDP per capita and population density were used to determine the initialised coastal protection standards in the base year, and for those cases where future adaptation is included (see "Impacts Model" section).

Socioeconomic projections for all scenarios were based on global regional changes following analysis by IMAGE Team (2002) and Nakićenović and Swart (2000), using the Special Report on Emission Scenarios A1 socioeconomic scenario. The 


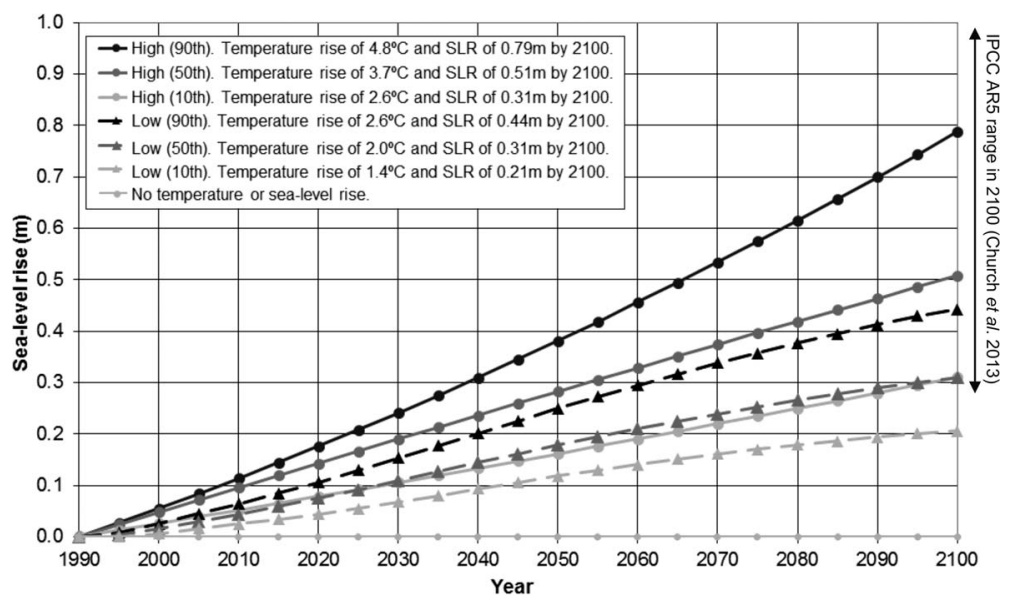

Figure 2. The high, low, and no sea-level-rise scenarios, with respect to 1980-99 for different percentiles of uncertainty. Temperature rise is with respect to preindustrial levels. Comparisons with sea-level rise are made with the IPCC AR5 report (Church et al., 2013), indicating global mean sea-level rise in 2100 with respect to 1986-2005.

A1 world represents one of rapid and successful economic development on a global scale, in which regional average income per capita increases. There is a strong commitment to market-based solutions, high investment in technology, education, and international mobility, with a balanced form of energy supplies (Nakićenović and Swart, 2000). Global population by 2050 grows to 8.6 billion people, before declining to 7.0 billion in 2100, which is lower than many other scenarios. The A1 scenario is most similar to the newer shared socioeconomic pathway 2 "middle of the road" scenario (Kriegler et al., 2012; O'Neill et al., 2014) (the data of the shared socioeconomic pathways only became available after all computations for the revised version of the current paper were finished.), and is one of several socioeconomic scenarios that may be paired with climate-change scenarios (O'Neill et al., 2014). For simplicity and because of lack of data, it was assumed that there was a uniform ratio of change for coastal segments per global region (i.e. if a segment had twice the GDP per capita or population density in 1995 compared with a neighbouring segment, this ratio would remain throughout the projection period).

\section{Impacts Model}

The DIVA (DINAS-COAST Consortium, 2006; McFadden et al., 2007; Vafeidis et al., 2008) model version 3.3.2 is an integrated model of coastal systems that assesses biophysical and socioeconomic impacts of SLR for different adaptation strategies. The model has been applied to analyse the impacts of SLR numerous times, including (1) the effect of high-end SLR at a global scale for land loss, displaced people, and adaptation costs (Nicholls et al., 2011); (2) the assessment of impacts due to uncertainties in data input (e.g., different sources of topographic and population data) for global flood risk (Hinkel et al., 2014); (3) how spatial variations in SLR affect impacts (Brown et al., 2016); (4) wetland changes (Spencer et al., 2016); and (5) wetland change, flooding, erosion, and saline intrusion in the Coral Triangle (McLeod et al., 2010).
The model is based on 12,148 coastline segments (average length $85 \mathrm{~km}$ ) that describe all of the world's coast, except Antarctica. This allows the model to capture the main coastal features, but because of the resolution of the global data sets it generalises complex coastlines, such as around lagoons, estuaries, or small islands. Biophysical and socioeconomic data are attributed to each segment. Elevation data were taken from the Shuttle Radar Topographic Mission, with a horizontal resolution of $90 \mathrm{~m}$ (Rabus et al., 2003).

For impact assessments, the effects of relative SLR (RSLR), i.e. the combined effects of eustatic SLR and vertical land movement (based on Peltier [2000]) and an additional $2 \mathrm{~mm} / \mathrm{y}$ for selected large subsiding deltas (based on a typical rate from Ericson et al., 2006) were analysed for each segment. Coastal flooding caused by RSLR together with storm surges were then assessed by analysing changes in extreme water levels from 1in-10-, 1-in-100-, and 1-in-1000-year events. Return periods in the DIVA model take account of (1) mean high tide level (based on harmonic constraints produced by XTIDE [www.flaterco. com/xtide]); (2) water level due to a change in barometric pressure; and (3) water level due to changes in wind setup (assuming an infinitely long, straight coast and uniform bottom slope, and estimated from wave observations based on Hurdle and Stive [1989]) as described in Muis et al. (2017). The total water levels for the extreme events were raised by the magnitude of SLR that was projected, so that the return period of a particular extreme water level was reduced. In this paper, two impact factors are considered in the 2080s (on the basis of a 30-y mean): (1) The ENPF/y (people/y) and (2) the total wetland loss $\left(\mathrm{km}^{2}\right)$.

To calculate the ENPF/y through submergence, first the number of people potentially exposed to an extreme event was calculated by integrating the population at set elevation intervals that are hydrologically connected to the sea on a digital elevation model. Then, to calculate the number of people flooded, DIVA integrates those exposed to flooding for different flood heights and weights by the probability of an extreme 
event occurring, taking account of defences (which themselves are dependent on socioeconomic conditions; see below).

To analyse wetland loss, 4315 sites of forested, freshwater, saltmarsh, and vegetated marshes wetlands plus mangrove sites were considered, checked, and verified. These were generated from multiple sources and atlases, including Hoozemans, Marchand, and Pennekamp (1993) and Spalding, Blasco, and Field (1997). Wetlands respond to SLR by horizontal inland migration, vertical elevation change, and transitions to other wetland types (McGranahan, Balk, and Anderson, 2007; Nicholls, Hoozemans and Marchand, 1999). The loss and change in coastal wetlands (based on their physical context: low/high unvegetated wetlands, saltmarsh, freshwater marsh, coastal forest, and mangroves), including migration of one wetland type to another, is assessed in the DIVA model in terms of wetland area, on the basis of McFadden et al. (2007). Wetland change in DIVA is a function of RSLR, tidal range, sediment supply, and migration (accommodation) space (i.e. the ability of a wetland to move inland without restriction). Migration space is reduced by the building of sea dikes (Feagin et al., 2010; Spencer et al., 2016). An ecological time lag exists when one wetland type converts to another (see McFadden et $a l ., 2007)$. DIVA does not evaluate the creation of new wetlands (e.g., through restoration, new engineering habitat creation, or through emerging mudflats) as sea levels rise.

Flood impacts are reduced via adaptation. In DIVA this is undertaken by modelling dikes. Modelled defences are stylised: dikes are used, as other types of defence (e.g., artificial dunes) are challenging to model on a global scale and also because the type of defences actually used in a particular region may be unknown. In reality, funds may not be available to implement defences, or there may be ecological considerations or other planning or management policies defining a set course of action.

Dikes are modelled for the base year (1995), following research from Yohe and Tol (2002). Since there are no empirical data on actual dike heights available at a global level, dike heights throughout the world were estimated through an econometric model calibrated to observed dike heights in northern Europe. The model estimated a society's demand for safety in terms of a design standard used to set dike height on the basis of per capita income and population density as key explanatory variables (Yohe and Tol, 2002). Demand for safety is another phrase for the flood risks deemed acceptable by the decision maker. This applies for each coastal segment in each time period. Acceptable risk is reinterpreted as a design standard used to set dike height. It was assumed that no dikes were built where there is very low population density $(<1$ person $/ \mathrm{km}^{2}$ ). For higher population densities, the demand-forsafety function was then applied increasingly using a logarithmic function, which applies half of the demand for safety at a population density of 20 persons $/ \mathrm{km}^{2}$, and $90 \%$ at a population density of 200 persons $/ \mathrm{km}^{2}$.

When analysing the benefits of climate-change mitigation (see "Results"), it was assumed that defences were not upgraded after 1995, and that no adaptation measures (e.g., nourishment, restoration) were undertaken for wetlands. Where the synergies between mitigation and adaptation are analysed (see "Discussion"), it was assumed that adaptation measures were upgraded with time (according to the socioeconomic conditions described above and in the "Discussion") and wetlands were nourished.

\section{RESULTS}

The ENPF/y and wetland losses were assessed using the DIVA model, taking account of sea-level and socioeconomic change, assuming that the modelled defences were not upgraded after the base year (1995).

\section{Expected Number of People Flooded Annually}

Figure 3 a shows that worldwide in the $2080 \mathrm{~s}$, for $0.19 \mathrm{~m}$ to $0.68 \mathrm{~m}$ of SLR (based on a 30-y mean and relative to 1980 1999), between 13 million and 123 million additional ENPF/y are projected compared with baseline levels in 1995 , assuming no upgrade in adaptation measures. For each percentile of SLR analysed, impacts under the low scenario were approximately half those of the high scenario. In the 2080 s, G-20 nations account for up to $54 \%$ of the global ENPF/ $\mathrm{y}$, and contain $55 \%$ of the global population. The G-20 proportion of the global ENPF/y is higher under the highSLR scenario compared with the low scenario. This is probably due to differences in the standard of protection in the base year and the number of people in the hazard zone. The top five G-20 countries for ENPF/y (expressed as a percentage of national total population) are China, India, Indonesia, Canada, and Russia. The countries least affected are Germany, Italy, and South Africa. Only China (where $0.3 \%$ of population could be affected under the high scenario and $0.2 \%$ under the low scenario) has a greater national proportion than the global population flooded. These findings differ from previous published results (e.g., Hinkel et al., 2014) because of different SLR and socioeconomic assumptions used.

\section{Wetland Loss}

Figure $3 \mathrm{~b}$ plots wetland loss with respect to 1995 levels, assuming no upgrade in adaptation measures. DIVA only considers wetland losses or transitions from one wetland type to another, not the emergence of new wetlands, so the data presented here depict the worst-case scenario. Virtually all projected losses are due to climate-induced SLR, rather than changes in relative land levels.

The benefits of climate-change mitigation are shown for the 2080 s, where global losses range between $179 \times 10^{3} \mathrm{~km}^{2}$ (for $0.19 \mathrm{~m}$ of rise) and $331 \times 10^{3} \mathrm{~km}^{2}$ (for $0.68 \mathrm{~m}$ of rise), equivalent to $21 \%$ and $39 \%$ of present global stock. G-20 nations contain two-thirds of the current global wetland stock. By the 2080s, approximately $60 \%$ of all losses (particularly coastal forest, saltmarsh, and freshwater marsh) are projected to be in G-20 countries regardless of emissions scenario. Globally, the dominant type of wetland loss is projected to be low unvegetated marshes (69\% lost globally, assuming no new wetlands are created), as these are low lying and have extensive coverage worldwide.

\section{DISCUSSION}

Following previous studies (e.g., Nicholls and Lowe, 2004), the SLR scenarios used in this paper demonstrate that under climate-change mitigation, the rate of SLR is reduced. This 
a)

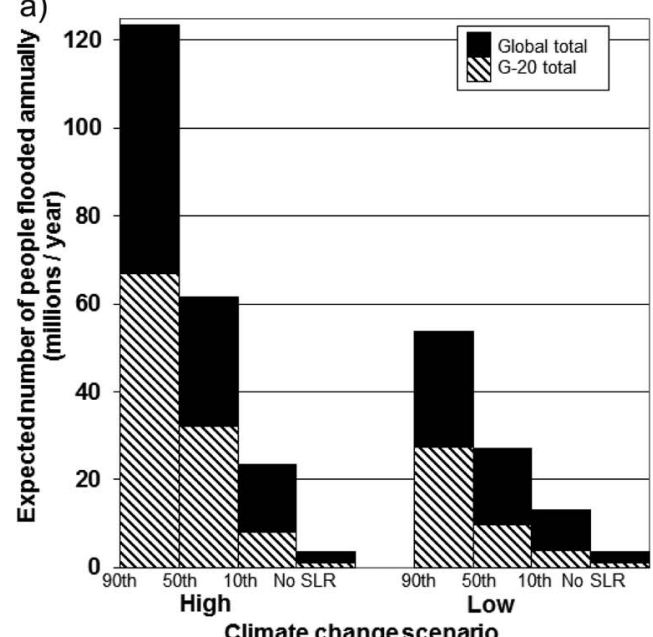

b)

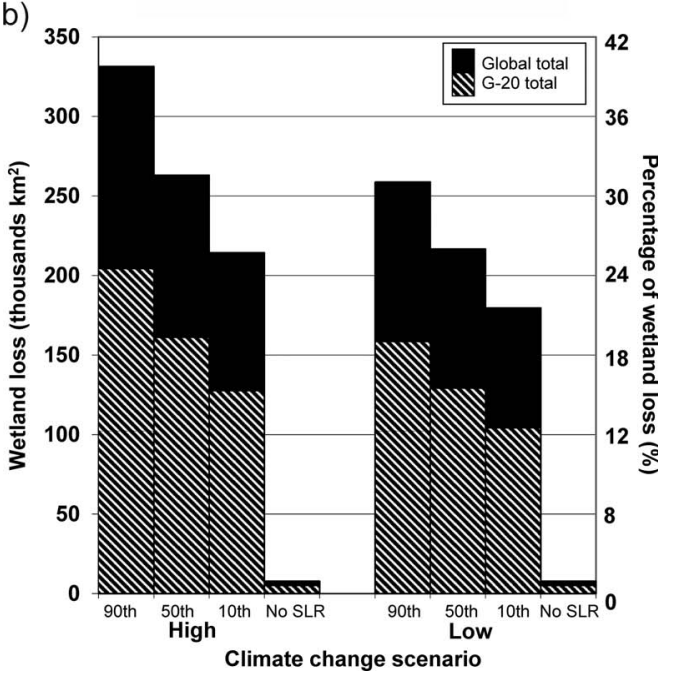

Figure 3. Impacts of sea-level rise at global level and G-20 countries (excluding the European Union) with respect to 1995 for different percentiles of uncertainty in sea-level rise in the 2080 s, for (a) expected number of people flooded annually, and (b) wetland loss.

paper shows that the associated coastal impacts are lessened and this becomes more apparent as the century progresses. Simultaneously, climate-change mitigation is projected to reduce many other adverse impacts (e.g., from temperature rise). Climate-change mitigation is particularly important for those human and natural environments that cannot adapt to the pace of change.

\section{Benefits of Climate-Change Mitigation and Assessment of Equity}

Equity lies with the concepts of sustainability, morality, legality and a fair arrangement in climate policy decisions (Fleurbaey et al., 2014). It brings intergenerational and intratemporal issues to managing risk (Stern, 2014). This includes common but differentiated responsibilities that recognise that states have variable levels of responsibility for climate change and in their capacities to cope, according to national circumstances (Brunnée and Streck, 2013). National circumstances and equity concern present-day responsibilities, capabilities, historic responsibilities, levels of economic development, resource availability, technology, costs, and international externalities. These all need to be considered in the broader context of sustainable development (Stern, 2014).

The worst impacts of climate change may be felt in nations different from those that are the largest historic emitters of greenhouse gases. Furthermore, in some cases the potential impacts of climate change may occur in nations least able to deal with the consequences. Hence, inequalities exist.

The benefits of climate-change mitigation (i.e. the difference between impacts under the high- and low-SLR scenarios, expressed as a percentage) will not be felt evenly worldwide because of the different national circumstances as noted above. This leads to questions of equity and the proportion of impacts projected for a particular country relative to its contributions to global greenhouse gas emissions or its ability to mitigate or adapt through financial means. This paper has focused on GDP per capita as a financial factor that indicates a nation's ability to adapt. In practice, finance may be channelled elsewhere, or used to reduce other adverse impacts of climate change. Figure $4(\mathrm{ENPF} / \mathrm{y})$ and Figure 5 (wetland loss) illustrate impacts in G20 countries under SLR in the 2080s with respect to their carbon dioxide emissions and GDP (at 2010 levels, as noted by World Bank 2016a,b,c).

Figure 4a plots GDP per capita and carbon dioxide emissions per capita, with the area of the circles representing the ENPF/ y. The larger the circle's area, the greater the projected ENPF/ $\mathrm{y}$. The lower left-hand side of the figure represents nations with lower income per capita and lower emissions per capita, which is more typical of developing nations. The upper right-hand side of the figure represents nations with both higher income per capita and higher emissions per capita. China and India have the largest populations at risk of flooding from SLR due to large populations living on low-lying coastal areas, but they have relatively low levels of emissions per capita in 2010. Over 15 million ENPF/y in China and 13 million ENPF/y in India are projected by the 2080s under the high-SLR scenario. With climate-change mitigation, this is reduced to 3.7 million and 5.0 million per year respectively, representing a decrease of nearly $75 \%$ in China and $61 \%$ in India. Hence climate-change mitigation could be very effective at reducing those people at risk from flooding. For ENPF/y, the countries that would benefit the least from climate change mitigation are Russia and Argentina.

Figure $4 \mathrm{~b}$ plots the percentage of global impacts for ENPF/y in the 2080s against the percentage of global carbon dioxide emissions for each G-20 nation. The diagonal line represents where the percentage of global impacts felt by a country (in the 2080s) would be the same as its percentage of global emissions. The farther away a country is plotted from the line, the less equitable the impacts (e.g., a nation may have greater impacts than its responsibility for, and proportion of, emissions). Only Indonesia and India are situated above the line. This indicates that they are projected to have greater impacts, in terms of people flooded, than the proportion of emissions that they have caused, under both the high- and low-SLR scenarios. Conversely, for all other nations situated below the line, their 
a)

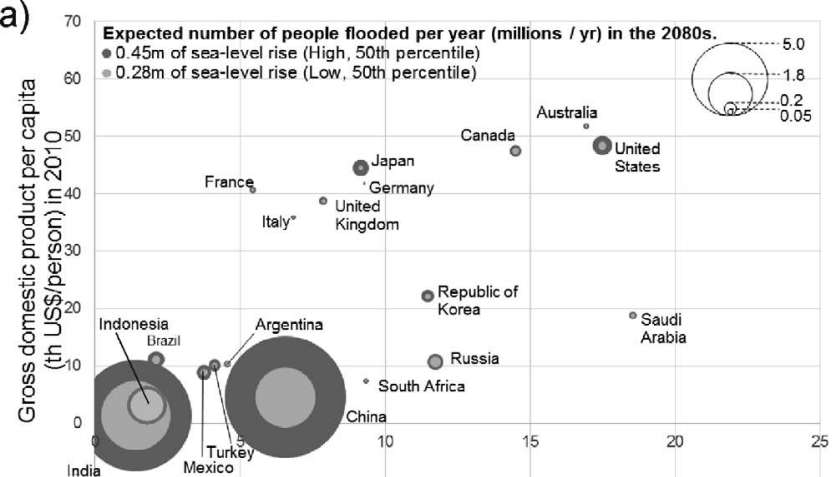

b)

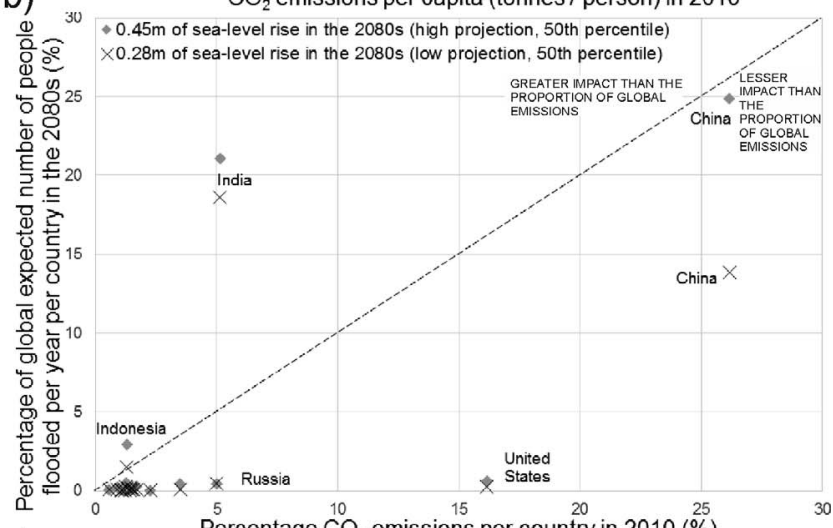

c)

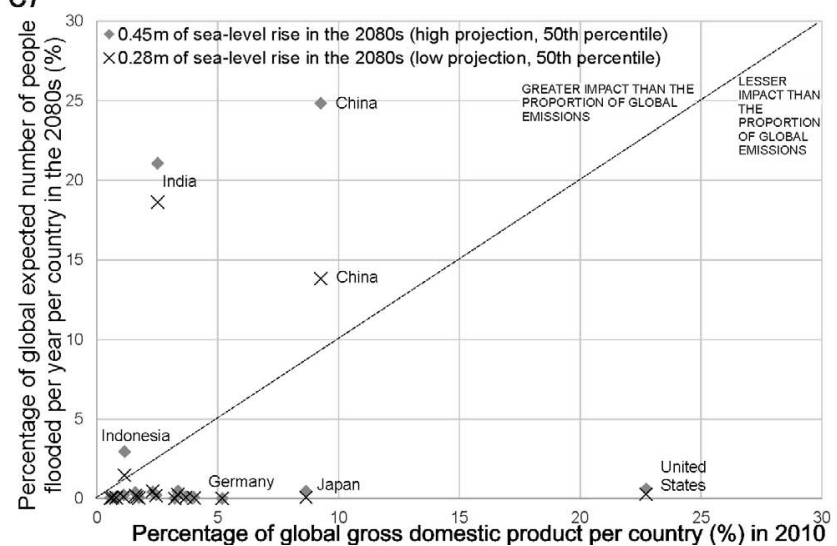

Figure 4. Expected number of people flooded annually for G-20 nations in the 2080s for high and low sea-level rise for (a) carbon dioxide emissions per capita and gross domestic product per capita (2010 values), (b) carbon dioxide emissions at national level as a percentage of global totals, and (c) gross domestic product at national level as a percentage of global totals.

proportion of impacts is less than their proportion of emissions, albeit with this quantity being very sensitive to the amount of SLR for China.

Figure 4c illustrates the relationship between ENPF/y and the global GDP. Again, countries plotted above the diagonal line indicate where the percentage of global impacts felt by a country (in the 2080s) would be more than its percentage of GDP, and below the line, vice versa. China and India, and to a lesser extent
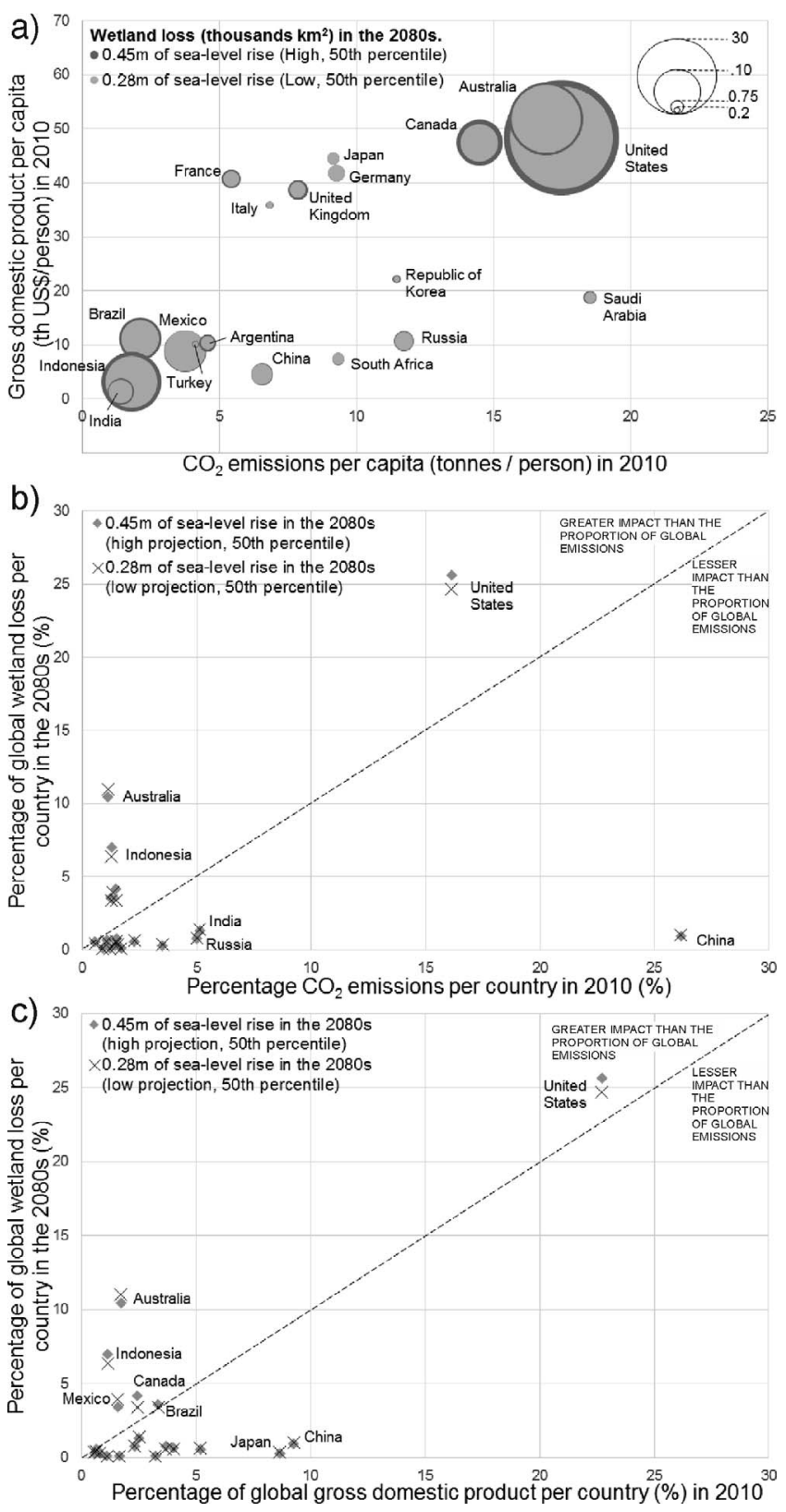

Figure 5. Wetland loss for G-20 nations in the 2080s for high and low sealevel rise for (a) carbon dioxide emissions per capita and gross domestic product per capita (2010 values), (b) carbon dioxide emissions at national level as a percentage of global totals, and (c) gross domestic product at national level as a percentage of global totals.

Indonesia, have a greater percentage of global ENPF/y projected than their percentage of GDP in 2010, albeit with considerable sensitivity to the amount of SLR in the case of China. This may mean that China, India, and Indonesia struggle to adapt unless they are able to prioritise coastal protection over other national costs. In contrast, the United States falls at an extreme position of proportionality, with a very high percentage of global GDP but a low percentage of global ENPF/y. 
Figure 5 plots the same parameters as Figure 4, but with wetland loss as the impact parameter. In absolute terms, the greatest losses are projected for the United States, Australia, Indonesia, Mexico, Brazil, and Canada (Figure 5a). Several countries with largest losses are those with the highest GDP per capita and emissions per capita. In relative terms, comparing national wetland areas in the 2080s with 1995 , the greatest percentage losses are projected for Italy, Turkey, and Japan. Figure $5 \mathrm{~b}$ plots the proportion of impacts in terms of the percentage of global wetland losses per country by the 2080s against the percentage of global carbon dioxide emissions in 2010. The United States, Australia, and Indonesia in particular all have a percentage of wetland loss that is greater than it would be for a perfectly proportional relationship with their percent contribution to global emissions (in 2010). In contrast, the percentages of global wetland loss for China, India, and Russia in particular are much less than their percentages of global emissions. When comparing the percentage of global wetland losses against the percentage of global GDP (Figure 5c), similar countries to Figure 5b emerged above or below the diagonal line.

The outcome of the analysis described above is different from that described by Hardy and Nuse (2016). Using different approaches and a much higher SLR of $6 \mathrm{~m}$, they found that historically the five nations most responsible for the current commitment to SLR (through historical emissions from 1850) were exposed to the greatest projected land loss. The differences in the proportions of impacts compared with historical emissions or with a national economic situation may therefore vary across impacts and for different time frames or magnitudes of SLR. This challenges the idea of how to define equity and to undertake a just response according to common but differentiated responsibilities. However, Hardy and Nuse (2016) and this study acknowledge that some countries will experience a double inequity with greater impacts compared with their contribution to emissions and economic growth (see Figures 4 and 5).

\section{Economic Effects of Climate-Change Mitigation}

Adaptation, as well as climate-change mitigation, has the ability to decrease local impacts. Adaptation could involve protection (e.g., build coastal defences), accommodation (e.g., houses mounted on stilts, crop diversification), or retreat (e.g., move buildings landward) (IPCC, 1990) depending on, for example, engineering capacity, geomorphology, ecology, legislation, and policy. So far, this study has assumed no upgrade to modelled defence levels since the base year. In reality, continued adaptation investment is almost certain.

In the 2080s under the low-SLR scenario presented here, around $95 \%$ of the G-20 total of ENPF/y and $41 \%$ of the global sum are from the nine non-Annex 1 countries. In 2010, nonAnnex 1 nations produced $40 \%$ of global carbon emissions (World Bank, 2016a). This suggests an overall near-proportional relationship of impacts to emissions in 2010 for nonAnnex 1 nations, but there is variation within this between non-Annex 1 countries. For wetlands, G-20 nations overall are projected to experience a greater proportion of global losses compared with non G-20 nations.
A nation's potential to adapt and mitigate for climate change may be linked to GDP/capita. Although this is a simple metric that does not take account of other cost burdens on a nation, it does provide a first-order view. Additionally, climate-change mitigation could potentially drive up the cost of energy and food, and thus slow economic growth affecting monetary resources (Clarke et al., 2014; Tavoni and Tol, 2010). This potentially leaves less money to be spent on coastal protection and other forms of adaptation to SLR, and Tol (2007) argued that these effects could be significant. Using a $0.21-\mathrm{m}$ rise in sea level by 2100 (the smallest rise in the low-SLR scenario range, representing stringent mitigation), and by assuming coastal defences are upgraded (see "Impacts Model" section), the ENPF/y and wetland losses under the standard socioeconomic scenario were compared with these impacts when the socioeconomic scenario had an $8 \%$ reduction in income per capita (based on Tavoni and Tol, 2010) throughout the 21st century as a potential effect of climate-change mitigation. As dike building is dependent on per capita income, the level of protection offered is reduced. Globally, over the 21st century, this comparison gives an increase in ENPF/y of $8 \%$ for the reduced income per capita. Of this increase, $5 \%$ is projected to occur in G-20 countries. ENPF/y for non-Annex 1 G-20 countries could increase by up to $9 \%$. Projected wetland losses particularly increase until the 2030s, even under modeled adaptation conditions. Global wetland loss under the low climate-change scenario (with reduced-income socioeconomic scenarios compared with the standard socioeconomic scenario) indicated an increase in losses of $20 \%$ in the 2030 s and $2 \%$ in the 2080 s. Thus, in the long term (multiple decades), a reduction in GDP per capita has limited effect on wetland losses. However, it must be noted that climate-change mitigation does provide valuable time for ecosystems to respond to change.

These results show that although climate-change mitigation is worthwhile, echoing Tol (2007), it must be appreciated that because of costs associated with climate-change mitigation, there is a potential implication that less money may be available for adaptation. However, for sea-level impacts, adaptation can reduce impacts by two orders of magnitude, especially in those countries where there are high coastal population densities. Adaptation is expected to be ongoing and offers substantial benefits in terms of impacts avoided. Combining adaptation and mitigation has been widely advocated (Nicholls et al., 2007; Wong et al., 2014) as a worthwhile method to reduce impacts (e.g., through wetland creation) but requires further consideration to be spatially effective.

\section{Implications}

Because of the commitment to SLR, an increase in coastal impacts will remain inevitable regardless of the level of climate-change mitigation. Mitigating for climate change potentially substantially reduces the projected ENPF/y. Wetlands are projected to benefit less from climate-change mitigation as this impact is more immediate (particularly if they are constrained from moving inland because of hard defences). 
Similar to Nicholls and Lowe (2004), the benefits and incentives to mitigate for climate change will be increasingly apparent for the effects of SLR over the longer term. Adaptation to reduce impacts today is required because of present-day extreme events, but as sea levels rise, further adaptation will be necessary. Adaptation combined in synergy with mitigation (Berry et al., 2015) may be an appropriate approach in many places to reduce impacts. For example, along suitable coastlines adaptation could include the reforestation of mangroves, which are known to abate the damaging effects of extreme water levels by acting as a buffer between land and sea, as well as providing multiple ecosystem services and absorbing carbon dioxide emissions (e.g., Polidoro et al., 2010; Shepard, Crain, and Beck, 2011). However, it is important to note that in some instances, adaptation could induce new problems, such as increased erosion down-drift of groynes or seawalls (Brown, Barton, and Nicholls, 2013), leading to reduced sediment levels or flooding in adjacent low-lying areas (Dawson et al., 2009).

For the maximum benefit in reducing impacts, adaptation should ideally consider all causes of change that could influence coastal flooding, not just SLR (Brown et al., 2014). This is noted, for example, in Jakarta, Indonesia, where Ward et al. (2011) found subsidence to be a major cause of flooding. By addressing the causes of subsidence alone, the number of people flooded would be reduced. For some areas, addressing subsidence could be more important than adapting to SLR. Similarly, human actions can potentially have a devastating effect on wetland loss, such as through the conversion of wetlands to agriculture or aquaculture or urban land use (Crooks et al., 2011; Polidoro et al., 2010; Upadhyay, Ranjan, and Singh, 2002; Valiela, Bowen, and York, 2001). Again, these losses could be of greater magnitude than losses projected from SLR alone. Thus, good practice suggests that effective adaptation needs to be integrated within the wider environment, taking account of multiple cross-sectoral threats (Newton, Carruthers, and Icely, 2012). This, however, is challenging to achieve.

\section{Further Considerations}

The scenarios used in this study are globally uniform projections of SLR that take account of a range of uncertainties, but SLR is additionally expected to have a pattern in response to steric and ice-melt contributions (Church et al., 2013). Taking into account spatial uncertainties in SLR arising from oceanographic spatial variations (but not including the spatial variations arising from the ice contribution) in the DIVA model, Brown et al. (2016) indicated that global impacts varied by $10 \%$ when contrasting an ensemble mean uniform SLR scenario with a patterned scenario. Differences in impacts under the patterned scenario were particularly enhanced around lowlying or populated areas. Church et al. (2013) indicates higher regional SLR from multiple drivers in East Asia and NW America/Canada from an ensemble mean of projections by 12 models, with high rises also reported along many parts of the Asian and African coastlines. Hence, non-Annex 1 countries may be at greater risk from SLR than projected here. The spatial variations in SLR noted above were obtained from global climate models. An additional caveat is that local coastal processes that may not be well represented by global models influence extreme water levels closer to the coastline.

Although the Paris Agreement (United Nations, 2015) has come into force, with the aim of stabilising surface temperature, sea levels are projected to rise for centuries. This reinforces the need for adaptation. There remain concerns that if there is a rapid dynamic change in ice sheets, sea levels could rise even higher. For example, from cryosphere evidence, DeConto and Pollard (2016) suggest that Antarctica alone could contribute $15 \mathrm{~m}$ of SLR equivalent over 500 years if emissions are unabated, with prolonged oceanic warming. Although this research remains uncertain, if such high rises in sea level were to occur, a fundamentally different approach would be needed for adaptation, for both developing and developed countries. This could have potential significant costs to coastal and inland areas, and would be strongly linked with socioeconomic development (Anthoff, Nicholls, and Tol, 2010). Hence, the need to mitigate is increasingly important, and even with mitigation, long-term adaptation plans should be considered.

In modelling impacts, much emphasis is placed on the uncertainties associated with SLR. At times, SLR is identified as the primary driver of change (e.g., Clough, Polaczyk, and Propato, 2016), but it is important to remember that multiple or compound uncertainties (Kettle, 2012; Moser, 2005) arise from other input scenarios (e.g., socioeconomic change, subsidence) and in numerically modelling the physical processes in impacts models (e.g., Hinkel et al., 2014). At a global scale, and sometimes at local scales, there lies much uncertainty into how best to adapt, or what autonomous adaptation is taking place that allows for greater accommodation of SLR. In this paper, GDP has been the focus of the financial ability to adapt. However, there are also numerous barriers that impede adaptation (Kettle, 2012), such as governance issues, leading to increasing uncertainty in future impacts. This could affect coastal development, which is itself a major source of uncertainty (Joshi et al., 2015). Furthermore, modelling wider economic effects of climate change is complex and reliant on many external actors. This paper has projected impacts for a defined set of scenarios, aimed at global or subglobal decision makers to determine who or what is vulnerable. At national scales, further assessments are required, with input data and uncertainties refined and reduced, so that optimal responses can be planned for the potential impacts of SLR.

\section{CONGLUSIONS}

Climate-change mitigation helps stabilise the rate of SLR, rather than the absolute magnitude of rise itself, over a meaningful policy time frame. By analysing the ENPF/y and wetland loss over the 21st century with a high-SLR scenario and a low-SLR scenario with no additional adaptation, coastal impacts have been reported globally and for G-20 nations, where the latter are responsible for the majority of the world's carbon dioxide emissions. This paper found that: (1) Climatechange mitigation means that some coastal impacts of SLR will be delayed or avoided, especially in the latter half of the century. The benefits of climate change mitigation depend on factors such as the magnitude of climate-change mitigation, and the uncertainties in response of SLR to climate and other 
social, institutional, economic, and environmental uncertainties. Benefits of climate-change mitigation will extend into the 22nd century and beyond. (2) G-20 nations with the highest emissions or GDP in 2010 often do not experience the greatest projected impacts. This often reflects the higher projected baseline standard of defences in these nations. Non-Annex 1 and developing nations, which generally have lower standards of defence, would benefit most from climate-change mitigation. Inequalities therefore exist. (3) There is less potential benefit of climate-change mitigation for avoiding wetland losses than for reducing the people flooded because of the different timescales over which the relevant coastal processes operate, together with differing land elevations involved. (4) Annex 1 G-20 nations have a greater proportion of the global wetland losses compared with non-Annex $1 \mathrm{G}-20$ nations, so stand to lose more unless new wetlands are created or emerge. (5) There may be some trade-offs between climate-change mitigation and adaptation that demand greater consideration in national and international assessments of the impacts of climate change.

Even with climate-change mitigation, significant impacts are projected to occur and adaptation is also essential in coastal zones. Future research could evaluate the dual benefits of climate-change mitigation and adaptation policies, considering the wider needs of coastal management.

\section{ACKNOWLEDGMENTS}

S.B. and R.J.N. were supported by funding from the United Kingdom Met Office (grant number P010376). A.K.P. and J.A.L. were partly supported by the Joint United Kingdom DECC/Defra Met Office Hadley Centre Climate Programme (GA01101). Further funding was provided by the European Commission's Seventh Framework Programme's collaborative project RISES-AM- (contract FP7-ENV-2013-two-stage603396) and via a joint United Kingdom Natural Environment Research Council and United Kingdom Government Department of Business Energy \& Industrial Strategy grant "ADJUST1.5", numbered NE/P01495X/1. Thanks to Jiayi Fang, University of Southampton, U.K. for assisting with editing the references.

\section{LITERATURE GITED}

Anthoff, D.; Nicholls, R.J., and Tol, R.S.J., 2010. The economic impact of substantial sea-level rise. Mitigation and Adaptation Strategies for Global Change, 15(4), 321-335.

Berry, P.M.; Brown, S.; Chen, M.; Kontogianni, A.; Rowlands, O.; Simpson, G., and Skourtos, M., 2015. Cross-sectoral interactions of adaptation and mitigation measures. Climatic Change, 128(3-4), 381-393.

Booth, B.B.B.; Bernie, D.; McNeall, D.; Hawkins, E.; Caesar, J.; Boulton, C.; Friedlingstein, P., and Sexton, D.M.H., 2013. Scenario and modelling uncertainty in global mean temperature change derived from emission-driven global climate models. Earth System Dynamics, 4(1), 95-108.

Booth, B.B.B.; Jones, C.D.; Collins, M.; Totterdell, I.J.; Cox, P.M.; Sitch, S.; Huntingford, C.; Betts, R.A.; Harris, G.R., and Lloyd, J., 2012. High sensitivity of future global warming to land carbon cycle processes. Environmental Research Letters, 7(2), 24002.

Brown, S.; Barton, M.E., and Nicholls, R.J., 2013. Shoreline response of eroding soft cliffs due to hard defences. Proceedings of the Institution of Civil Engineers-Maritime Engineering, 167(1), 314.
Brown, S.; Nicholls, R.J.; Hanson, S.; Brundrit, G.; Dearing, J.A.; Dickson, M.E.; Gallop, S.L.; Gao, S.; Haigh, I.D.; Hinkel, J.; Jiménez, J.A.; Klein, R.J.; Kron, W.; Lázár, A.N.; Neves, C.F.; Newton, A.; Pattiaratachi, C.; Payo, A.; Pye, K.; Sánchez-Arcilla, A.; Siddall, M.; Shareef, A.; Tompkins, E.L.; Vafeidis, A.T.; van Maanen, B.; Ward, P.J., and Woodroffe, C.D., 2014. Shifting perspectives on coastal impacts and adaptation. Nature Climate Change, 4(9), 752-755.

Brown, S.; Nicholls, R.J.; Lowe, J.A., and Hinkel, J., 2016. Spatial variations of sea-level rise and impacts: An application of DIVA. Climatic Change, 134(3), 403-416.

Brunnée, J. and Streck, C. 2013. The UNFCCC as a negotiation forum: Towards common but more differentiated responsibilities. Climate Policy, 13(5), 589-607. doi: 10.1080/14693062.2013.822661

Chen, J., 1997. The impact of sea-level rise on China's coastal areas and its disaster hazard evaluation. Journal of Coastal Research, 13(3), 925-930.

Church, J.A.; Clark, P.U.; Cazenave, A.; Gregory, J.M.; Jevrejeva, S.; Levermann, A.; Merrifield, M.A.; Milne, G.A.; Nerem, R.S.; Nunn, P.D.; Payne, A.J.; Pfeffer, W.T.; Stammer, D., and Unnikrishnan, A.S., 2013. Sea level change. In: Stocker, T.F.; Qin, D.; Plattner, G.K.; Tignor, M.; Allen, S.K.; Boschung, J.; Nauels, A.; Xia, Y.; Bex, V., and Midgle, P.M. (eds.), Climate Change 2013: The Physical Science Basis. Contribution of Working Group I to the Fifth Assessment Report of the Intergovernmental Panel on Climate Change. Cambridge: Cambridge University Press, pp. 1137-1216.

Church, J.A. and White, N.J., 2011. Sea-level rise from the late 19th to the early 21 st century. Surveys in Geophysics, 32(4-5), 585-602.

CIESIN (Center for International Earth Science Information Network, Columbia University); IFPRI (International Food Policy Research Institute); The World Bank, and CIAT (Centro Internacional De Agricultura Tropical), 2000. Global Rural-Urban Mapping Project, Version 1 (GRUMPv1): Population Density Grid. Palisades, New York: NASA Socioeconomic Data and Applications Center (SEDAC).

Clarke, L.; Jiang, K.; Akimoto, K.; Babiker, M.; Blanford, G.; FisherVanden, K.; Hourcade, J.-C.; Krey, V.; Kriegler, E.; Löschel, A.; McCollum, D.; Paltsev, S.; Rose, S.; Shukla, P.R.; Tavoni, M.; van der Zwaan, B.C.C., and van Vuuren, D.P., 2014. Assessing transformation pathways. In: Edenhofer, O.; Pichs-Madruga, R.; Sokona, Y.; Farahani, E.; Kadner, S.; Seyboth, K.; Adler, A.; Baum, I.; Brunne, S.; Eickemeier, P.; Kriemann, B.; Savolainen, J.; Schlömer, S.; von Stechow, C.; Zwickel, T., and Minx, T.C. (eds.), Climate Change 2014: Mitigation of Climate Change. Contribution of Working Group III to the Fifth Assessment Report of the Intergovernmental Panel on Climate Change. Cambridge: Cambridge University Press, pp. 413-510.

Clough, J.; Polaczyk, A., and Propato, M., 2016. Modeling the potential effects of sea-level rise on the coast of New York: Integrating mechanistic accretion and stochastic uncertainty Environmental Modelling \& Software, 84, 349-362.

Crooks, S.; Tamelander, J.; Laffoley, D., and March, J.V., 2011. Mitigating climate change through restoration and management of coastal wetlands and near-shore marine ecosystems-Challenges and opportunities. Environment Department Papers, Marine Ecosystem Series Paper 121, 69p.

Dasgupta, S.; Laplante, B.; Meisner, C.; Wheeler, D., and Yan, J., 2009. The impact of sea level rise in developing countries: A comparative anlaysis. Climatic Change, 93(3), 379-388.

Dawson, R.J.; Dickson, M.E.; Nicholls, R.J.; Hall, J.W.; Walkden, M.J. A.; Stansby, P.K.; Mokrech, M.; Richards, J.; Zhou, J.; Milligan, J.; Jordan, A.; Pearson, S.; Rees, J.; Bates, P.D.; Koukoulas, S., and Watkinson, A.R., 2009. Integrated analysis of risks of coastal flooding and cliff erosion under scenarios of long term change. Climatic Change, 95(1-2), 249-288.

DeConto, P. and Pollard, D., 2016. Contribution of Antarctica to past and future sea-level rise. Nature, 531(7596), 591-597.

Den Elzen, M.G.J.; Hof, A.F., and Roelfsema, M., 2013. Analysing the greenhouse gas emission reductions of the mitigation action plans by non-Annex I countries by 2020. Energy Policy, 56, 633-643

DINAS-COAST Consortium, 2006. DIVA 1.5.5. Potsdam Institute for Climate Impact Research. http://www.diva-model.net/ 
Ericson, J.P.; Vorosmarty, C.J.; Dingman S.L.; Ward L.G., and Meybeck, M., 2006. Effective sea-level rise and deltas: Causes of change and human dimension implications. Global amd Planetary Change, 50(1-2), 63-82.

Feagin, R.A.; Martinez, M.L.; Mendoza-Gonzalez, G., and Costanza, R., 2010. Salt marsh zonal migration and ecosystem service change in response to global sea level rise: A case study from an urban region. Ecology and Society, 15(4), article 14. http://www. ecologyandsociety.org/vol15/iss4/art14/

Fleurbaey, M.; Kartha, S.; Bolwig, S.; Chee, Y.L.; Chen, Y.; Corbera, E.; Lecocq, F.; Lutz, W.; Muylaert, M.S.; Norgaard, R.B.; Okereke, C., and Sagar, A.D., 2014: Sustainable development and equity. In Edenhofer, O.; Pichs-Madruga, R.; Sokona, Y.; Farahani, E.; Kadner, S.; Seyboth, K.; Adler, A.; Baum, I.; Brunner, S. Eickemeier, P.; Kriemann, B.; Savolainen, J.; Schlömer, S.; von Stechow, S.; Zwickel, T., and Minx, J.C. (eds), Climate Change 2014: Mitigation of Climate Change. Contribution of Working Group III to the Fifth Assessment Report of the Intergovernmental Panel on Climate Change. Cambridge: Cambridge University Press, pp. 283-350.

Gordon, C.; Cooper, C.; Senior, C.A.; Banks, H.; Gregory, J.M.; Johns, T.C.; Mitchell, J.F.B., and Wood, R.A., 2000. The simulation of SST, sea ice extents and ocean heat transports in a version of the Hadley Centre coupled model without flux adjustments. Climate Dynamics, 16(2-3), 147-168.

Gutierres, F.; Teodoro, A.C.; Reis, E., and Neto, C., 2016. Remote sensing technologies for the assessment of marine and coastal ecosystems. In: Finkl, C. and Makowski, C. (eds.), Seafloor Mapping along Continental Shelves: Research and Techniques for Visualizing Benthic Environments. Dordrecht, The Netherlands: Springer, pp. 69-104.

Hardy, R.D. and Nuse, B.L., 2016. Global sea-level rise: Weighing country responsibility and risk. Climatic Change, 137(3), 333-345.

Hauer, M.E.; Evans, J.M., and Mishra, D.R., 2016. Millions projected to be at risk from sea-level rise in the continetial United States. Nature Climate Change, 6, 691-695.

Hinkel, J.; Lincke, D.; Vafeidis, A.T.; Perrette, M.; Nicholls, R.J.; Tol, R.S.J.; Marzeion, B.; Fettweis, X.; Ionescu, C., and Levermann, A., 2014. Coastal flood damage and adaptation costs under 21st century sea-level rise. Proceedings of the National Academy of Sciences of the United States of America, 111(9), 3292-3297.

Hoozemans, F.M.J.; Marchand, M., and Pennekamp, H.A., 1993. Sea Level Rise: A Global Vulnerability Assessment-Vulnerability Assessments for Population, Coastal Wetlands and Rice Production on a Global Scale, 2nd edition. Delft, The Netherlands: Delft Hydraulics and The Hague, The Netherlands: Rijkswaterstaat, $184 \mathrm{p}$

Hurdle, D.P. and Stive, R.J.H., 1989. Revision of SPM 1984 wave hindcast model to avoid inconsistencies in engineering application. Coastal engineering, 12(4), 339-351.

IMAGE Team, 2002. Image 2.2. http://www.mnp.nl/en/themasites/ image/index.html

IPCC (Intergovernmental Panel on Climate Change), 1990. Strategies for Adaptation to Sea Level Rise. Report of the Coastal Zone Management Subgroup. Response Strategies Working Group of the Intergovernmental Panel on Climate Change. The Hague, The Netherlands: Ministry of Transport, Public Works and Water Management. 130p.

Jevrejeva, S.; Grinsted, A., and Moore, J.C., 2009. Anthropogenic forcing dominates sea level rise since 1850. Geophysical Research Letters, 36(20), L20706.

Joshi, S.R.; Vielle, M.; Babonneau, F.; Edwards, N.R., and Holden, P.B., 2015. Physical and economic consequences of sea-level rise: A coupled GIS and CGE anlaysis under uncertainties. Environmental and Resources Economics, 65(4), 813-839.

Kettle, N.P., 2012. Exposing compounding uncertainties in sea level rise assessments. Journal of Coastal Research, 28(1), 161-173.

Kirwan, M.L. and Megonigal, J.P., 2013. Tidal wetland stability in the face of human impacts and sea-level rise. Nature Climate Change, $504,53-60$.

Kriegler, E.; O'Neill, B.C.; Hallegatte, S.; Kram, T.; Lempert, R.J.; Moss, R.H., and Wilbanks, T., 2012. The need for and use of socio- economic scenarios for climate change analysis: A new approach based on shared socio-economic pathways. Global Environmental Change, 22(4), 807-822.

McFadden, L.; Nicholls, R.J.; Vafeidis, A., and Tol, R.S.J., 2007. A methodology for modeling coastal space for global assessment. Journal of Coastal Research, 23(4), 911-920.

McGranahan, G.; Balk, D., and Anderson, B., 2007. The rising tide: Assessing the risks of climate change and human settlements in low elevation coastal zones. Environment and Urbanization, 19(1), $17-37$.

McLeod, E.; Hinkel, J.; Vafeidis, A.T.; Nicholls, R.J.; Harvey, N., and Salm, R., 2010. Sea-level rise vulnerability in the countries of the Coral Triangle. Sustainability Science, 5(2), 207-222.

Meehl, G.A.; Stocker, T.F.; Collins, W.D.; Friedlingstein, P.; Gaye, A.T.; Gregory, J.M.; Kitoh, A.; Knutti, R.; Murphy, J. M.; Noda, A.; Raper, S.C.B.; Watterson, I.G.; Weaver, A.J., and Zhao, Z.C., 2007. Global climate projections. In: Solomon, S.; Qin, D.; Manning, M.; Chen, Z.; Marquis, M.; Averyt, K.B.; Tignor, M., and Miller, H.L. (eds.). Climate Change 2007: The Physical Science Basis. Contribution of Working Group I to the Fourth Assessment Report of the Intergovernmental Panel on Climate Change. Cambridge: Cambridge University Press, pp. 433-497.

Moser, S.C., 2005. Impact assessments and policy responses to sealevel rise in three US states: An exploration of human-dimension uncertainties. Global Environmental Change, 15(4), 353-369.

Muis, S.; Verlaan, M.; Nicholls, R.J.; Brown, S.; Hinkel, J.; Lincke, A.T.; Vafeidis, A.T.; Scussolini, H.C.; Winsemius, H.C., and Ward, P.J., 2017. A comparison of two global datasets of extreme sea levels and resulting flood exposure. Earth's Future, 5, 379-392.

Nakicenovic, N. and Swart, R. (eds.), 2000. Special Report on Emissions Scenarios. Cambridge, UK: Cambridge University Press, 612p.

Natural Earth, 2017. 1:50-m Manual Shaded Relief. Version 3.3.0. http://www.naturalearthdata.com/downloads/50m-raster-data/ 50m-manual-shaded-relief/

Newton, A.; Carruthers, T.J.B., and Icely, J., 2012. The coastal syndromes and hotspots on the coast. Estuarine, Coastal and Shelf Science, 96(1), 39-47.

Nicholls, R.J.; Brown, S.; Goodwin, P.; Wahl, T.; Lowe, J.; Solan, M.; Godbold, J.; Haigh, I.D.; Lincke, D.; Hinkel, J.; Wolff, C., and Merkens, J.-L., 2018. Stabilization of global temperature at $1.5^{\circ} \mathrm{C}$ and $2.0^{\circ} \mathrm{C}$ : Implications for coastal areas. Philosophical Transactions of The Royal Society A, 376(2119), 20160448.

Nicholls, R.J.; Hoozemans, F.M., and Marchand, M., 1999. Increasing flood risk and wetland losses due to global sea-level rise: Regional and global analyses. Global Environmental Change, 9, S69-S87.

Nicholls, R.J. and Lowe, J.A., 2004. Benefits of mitigation of climate change for coastal areas. Global Environmental Change, 14(3), 229-244.

Nicholls, R.J.; Marinova, N.; Lowe, J.A.; Brown, S.; Vellinga, P.; de Gusmão, D.; Hinkel, J., and Tol, R.S.J., 2011. Sea-level rise and its possible impacts given a "beyond $4^{\circ} \mathrm{C}$ world" in the twenty-first century. Philosophical Transactions. Series A, Mathematical, Physical, and Engineering Sciences, 369(1934), 161-181.

Nicholls, R.J.; Wong, P.P.; Burkett, V.R.; Codignotto, J.O.; Hay, J.E. McLean, R.F.; Ragoonaden, S., and Woodroffe, C.D., 2007. Coastal systems and low-lying areas. In: Parry, M.L.; Canziani, O.F.; Palutikof, J.P.; van der Linden, P.R., and Hanson, C.E. (eds.), Climate Change 2007: Impacts, Adaptation and Vulnerability. Contribution of Working Group II to the Fourth Assessment Report of the Intergovernmental Panel on Climate Change, Cambridge: Cambridge University Press, pp 315-356.

Nicholls, R.J.; Woodroffe, C., and Burkett, V., 2009. Coastline degradation as an indicator of global change. In: Letcher, T.M (ed.), Climate Change. Observed Impacts on Planet Earth. Amsterdam: Elsevier, pp. 409-424.

O’Neill, B.C.; Kriegler, E.; Riahi, K.; Ebi, K.L.; Hallegatte, S.; Carter, T.R.; Mathur, R., and van Vuuren, D.P., 2014. A new scenario framework for climate change research: The concept of shared socioeconomic pathways. Climatic Change, 122(3), 387-400.

Peltier, W.R., 2000. Glacial isostatic adjustment corrections. In Douglas, B.C.; Kearney, M.S., and Leatherman, S.P. (eds.), Sea 
Level Rise, History and Consequences. San Diego, California: Academic, pp. 65-95.

Polidoro, B.A.; Carpenter, K.E.; Collins, L.; Duke, N.C.; Ellison, A.M.; Ellison, J.C.; Farnsworth, E.J.; Fernando, E.S.; Kathiresan, K.; Koedam, N.E.; Livingstone, S.R.; Miyagi, T.; Moore, G.E.; Nam, V.N.; Ong, J.E.; Primavera, J.H.; Salmo, S.G.; Sanciangco, J.C.; Sukardjo, S.; Wang, Y., and Yong, J.W.H., 2010. The loss of species: Mangrove extinction risk and geographic areas of global concern. PLoS ONE, 5(4), e10095.

Rabus, B.; Eineder, M.; Roth, A., and Bamler, R., 2003. The shuttle radar topography mission -A new class of digital elevation models acquired by spaceborne radar. ISPRS Journal of Photogrammetry and Remote Sensing, 57(4), 241-262.

Shepard, C.C.; Crain, C.M., and Beck, M.W., 2011. The protective role of coastal marshes: A systematic review and meta-analysis. PLoS ONE, 6(11), e27374

Small, C. and Nicholls, R.J., 2003. A global analysis of human settlement in coastal zones. Journal of Coastal Research, 19(3), 584-599.

Spalding, M.D.; Blasco, F., and Field, C.D. (eds.), 1997. World Mangrove Atlas. Compiled by UNEP-WCMC, in collaboration with the International Society for Mangrove Ecosystems (ISME), version 3. Okinawa, Japan: International Society for Mangrove Ecosystems, 178p. https://archive.org/details/worldmangroveatl97spal

Spencer, T.; Schuerch, M.; Nicholls, R.J.; Hinkel, J.; Lincke, D.; Vafeidis, A.T.; Reef, R.; McFadden, L., and Brown, S., 2016. Global coastal wetland change under sea-level rise and related stresses: The DIVA wetland change model. Global and Planetary Change, 139, 15-30.

Stern, N. 2014. Ethics, equity and the economics of climate change. Paper 2: Economics and politics. Economics and Philosophy, 30(3), 445-501. doi:10.1017/S0266267114000303

Swart, R. and Raes, F., 2007. Making integration of adaptation and mitigation work: Mainstreaming into sustainable development policies? Climate Policy, 7, 288-303.

Tavoni, M. and Tol, R.S.J., 2010. Counting only the hits? The risk of underestimating the costs of stringent climate policy: A letter. Climatic Change, 100(3), 769-778.

Tol, R.S.J., 2007. The double trade-off between adaptation and mitigation for sea level rise: An application of FUND. Mitigation and Adaptation Strategies for Global Change, 12(5), 741-753.

United Nations, 2011. Compilation of economy-wide emission reduction targets to be implemented by parties included in Annex I to the
Convention. Bonn, United Nations. http://unfccc.int/resource/docs/ 2011/sb/eng/inf01r01.pdf

United Nations, 2015. Adoption of the Paris Agreement. Paris: United Nations Framework Convention on Climate Change. http://unfccc. int/resource/docs/2015/cop21/eng/109r01.pdf

UNFCCC (United Nations Framework Convention on Climate Change), 2013. Parties and Observers. http://unfccc.int/parties_ and_observers/items/2704.php

Upadhyay, V.P.; Ranjan, R., and Singh, J.S., 2002. Human-mangrove conflicts: The way out. Current Science, 83(11), 1328-1336.

Vafeidis, A.T.; Nicholls, R.J.; McFadden, L.; Tol, R.S.J.; Hinkel, J.; Spencer, T.; Grashoff, P.S.; Boot, G., and Klein, R.J.T., 2008. A new global coastal database for impact and vulnerability analysis to sea-level rise. Journal of Coastal Research, 24(4), 917-924.

Valiela, I.; Bowen, J.L., and York, J.K., 2001. Mangrove forests: One of the world's threatened major tropical environments. BioScience, 51(10), 807-815.

Ward, P.J.; Marfai, M.A.; Yulianto, F.; Hizbaron, D.R., and Aerts, J.C.J.H., 2011. Coastal inundation and damage exposure estimation: A case study for Jakarta. Natural Hazards, 56(3), 899916.

Wong, P.P.; Losada, I.J.; Gattuso, J.P.; Hinkel, J.; Khattabi, A.; McInnes, K.L.; Saito, Y., and Sallenger, A., 2014. Coastal systems and low-lying areas. In: Field, C.B.; Barros, V.R.; Dokken, D.J.; Mach, K.J.; Mastrandrea, M.D.; Bilir, T.E.; Chatterjee, M.; Ebi, K.L.; Estrada, Y.O.; Genova, R.C.; Girma, B.; Kissel, E.S.; Levy, A.N.; MacCracken, S.; Mastrandrea, P.R., and White, L.L. (eds.), Climate Change 2014: Impacts, Adaptation, and Vulnerability. Part A: Global and Sectoral Aspects. Contribution of Working Group II to the Fifth Assessment Report of the Intergovernmental Panel on Climate Change. Cambridge: Cambridge University Press, pp 361-409.

World Bank, 2016a. Data. $\mathrm{CO}_{2}$ Emissions (kt). http://data.worldbank. org/indicator/EN.ATM.CO2E.KT

World Bank, 2016b. Data. GDP (Current US\$). http://data.worldbank. org/indicator/NY.GDP.MKTP.CD

World Bank, 2016c. Data. Population, Total. http://data.worldbank. org/indicator/SP.POP.TOTL

Yohe, G. and Tol, R.S.J., 2002. Indicators for social and economic coping capacity: Moving towards a working definition of adaptive capacity. Global Environmental Change, 12(1), 25-40. 